\section{REVISTA Mario Alario JURIDICA D'Filippo}

\title{
Los comandantes de las FARC-EP ante la JEP en el plano del derecho penal del enemigo
}

\author{
The commanders of the FARC-EP before the JEP, in the plan of the \\ criminal law of the enemy
}

Irina De La Candelaria Aguilar Muentes 1 ic

Universidad libre - Colombia

\section{RESUMEN}

El objetivo propuesto en esta investigación consiste, en establecer si los excomandantes de las Farc-EP "Iván Márquez", "Jesús Santrich" y "El Paisa" frente a las distorsiones, cambios y desnaturalización sufridos por la Justicia Especial para la Paz, tienen a esta justicia restaurativa colombiana en el plano del derecho penal del enemigo, para explicar su ruptura con este sistema integral. La metodología empleada fue la de la investigación jurídica pura y básica para el derecho, y las técnicas de recolección de la información fueron las secundarias ya que se realizaron fichas bibliográficas que permitieron realizar un análisis de contenido a libros, capítulos de libros y artículos científicos que condescienden en establecer el estado de la discusión sobre el tema indagado. Hallamos que el Derecho penal en Colombia, está destinado a tipificar las violaciones a la ley, que se dan en una comunidad como la nuestra donde reina la marginalidad, la miseria y la exclusión, este es el derecho penal del ciudadano; es por ello, que cuando surgen personas que se alzan en armas contra el Estado para resolver los problemas sociales, los conflictos políticos, luchando contra la hegemonía y la oligarquía, que busca el mantenimiento del poder político, se utiliza el derecho penal acusándole de enemigo del régimen como ha ocurrido con los comandantes de las FARC-EP, pero al mismo tiempo se utiliza a favor de las clases integradas al sistema jurídico, como sus excombatientes de menor rango; de esta manera funciona un derecho penal de dos caras: Uno extraordinario cuyo destinatario es el enemigo, para el caso que nos ocupa, los comandantes y otro ordinario, aplicado a los excombatientes de las otrora guerrillas que se integraron al partido político: Las FARC.

Palabras clave: Guerrillas; conflicto armado; acuerdo de paz; justicia restaurativa; derecho penal del enemigo.

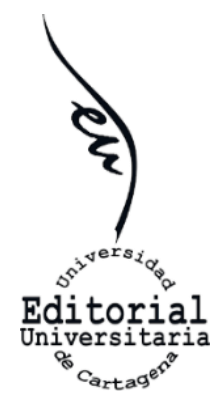

\begin{abstract}
The objective proposed in this investigation, is to establish whether the excommanders of the FARC-EP alias "Iván Márquez", alias "Jesús Santrich" and alias "El Paisa" in the face of the distortions, changes and denaturalization suffered by the Special Justice for the Peace, they have this Colombian restorative justice at the level of the enemy's criminal law, to explain their break

\footnotetext{
${ }^{1}$ Abogado. Especialista y Magister en Derecho Penal y Criminología (C). Estudiante de Maestría en Derecho Penal y Criminología, Universidad Libre Seccional Barranquilla. iría.gui@ hotmail.com
} 
with this comprehensive system. The methodology used was that of pure and basic legal research for the law, and the information gathering techniques were secondary since bibliographic records were made that allowed a content analysis of books, book chapters and scientific articles that were carried out, they condescend to establish the status of the discussion on the subject being investigated. We found that criminal law in Colombia is intended to classify violations of the law, which occur in a community like ours where marginality, misery and exclusion reign. This is the criminal law of the citizen; That is why when people rise up in arms against the State to solve social problems, political conflicts, fighting against hegemony and the oligarchy, which seeks to maintain political power, criminal law is used accusing it of being an enemy. of the regime, as has happened with the FARC-EP commanders, but at the same time it is used in favor of the classes integrated into the legal system, such as its lower-ranking ex-combatants; In this way, a two-sided criminal law works: an extraordinary one whose addressee is the enemy, for the case at hand, the commanders, and another ordinary one, applied to ex-combatants of the former guerrillas who joined the political party: the FARC.

Keywords: Guerrillas; armed conflict; peace agreement; restorative justice; enemy criminal law.

\section{INTRODUCCIÓN}

Este articulo científico, es producto del trabajo de grado de Maestría en Derecho Penal y Criminología en la Universidad Libre Seccional Barranquilla, titulado IVÁN MÁRQUEZ”, "JESÚS SANTRICH” Y "EL PAISA” EXGUERRILLEROS DE LAS FARC-EP Y LA JEP, EN EL PLANO DEL DERECHO PENAL DEL ENEMIGO, y en él, se desarrolla el tercer capítulo en el cual se desenvuelve el tercer objetivo específico, que consiste en realizar un análisis hermenéutico del derecho penal del enemigo, para reflexionar sobre el retiro de estos excomandantes y principales cabecillas de este grupo guerrillero ahora desmovilizado, de la jurisdicción y competencia de la Justicia Especial para la Paz.

Y es que, en el acuerdo de paz, que se firmó el 30 de noviembre de 2016, entre el expresidente Santos y Alias "Timochenko" el máximo líder del extinto grupo guerrillero FARC -EP, se estipuló que los crímenes cometidos hasta la firma del Acuerdo serían juzgados por la Justicia Especial para la Paz, como justicia transicional y los crimines cometidos después de esa fecha, serían procesados por la justicia ordinaria y si hay quienes tengan cargos en el extranjero, serían extraditados.

Los guerrilleros rasos, los excombatientes, responden por conductas delictivas pequeñas, pero los excomandantes que estén involucrados en la comisión de hechos punibles de alto impacto en el país, durante la ocurrencia de la confrontación armada entre las FARC y las Fuerzas Armadas de 
Colombia, tales como, quienes participaron en el acto del carro bomba, que impacto al Club El Nogal en Bogotá, hecho ocurrido en el año 2003, serían ser procesados por crímenes de guerra.

Además de que los desmovilizados de las FARC, deben responder ante la Justicia Especial para la Paz (JEP a partir de este momento) por acciones tales como: El reclutamiento de menores, actividad realizada para que ingresaran a esta guerrilla y participaran de la confrontación armada. También quienes secuestraron -colombianos o extranjeros- para pedir dinero a sus familiares y que posteriormente fueron asesinados, o participaron en hechos de violencia sexual, inclusive, entre las guerrilleras que integraban al grupo armado, así como quienes sometieron a tratos crueles e inhumanos a sus propios combatientes, por ello, antes que ser extraditados, las victimas pedían que los excomandantes de las FARC fuesen procesados ante el sistema de justicia restaurativa, estipulada en el Acuerdo de Paz, firmado durante el gobierno de Juan Manuel Santos.

Desde hace 3 años, los exguerrilleros que además de desmovilizarse se acogieron a la JEP, tienen un esquema de seguridad provisto por la Unidad Nacional de Protección (UNP), y todos sus movimientos han sido monitoreados y están a disposición de las autoridades, así mismo, han suscrito actas de compromiso con la JEP y han hecho reiteradas declaraciones públicas comprometiéndose con el proceso de paz y en especial con todo lo que tiene que ver con el punto $5^{\circ}$ del acuerdo de paz, que tiene como centro a las víctimas del conflicto armado.

Pero la Justicia Especial para la Paz, JEP, inició su proceso legal con un endeble sistema judicial, para juzgar los ilícitos que estos desmovilizados habían cometido, durante los años de guerra interna que vivió Colombia y en el cual se enfrentaban como ejército irregular con las Fuerzas Armadas de este país, pero aun así, extraditar a los comandantes, era no garantizar el proceso de verdad, y de la rendición de cuentas por los crímenes de guerra, en contra de las miles de víctimas que dejo esta extinta guerrilla.

Antes de que la JEP expulsara a los exjefes de las FARC - EP, aquí mencionados, ellos mismos anunciaron que se iban del proceso de paz y adujeron que por tanto esta justicia restaurativa no los cobijaba, entre otras cosas porque ellos iban a estructurar un nuevo grupo guerrillero, como el extinto FARC - EP, es de allí que la pregunta que oriente esta investigación es: ¿La ruptura con la Justicia Especial para la Paz de los excomandantes de las FARC, se da porque tienen a esta justicia restaurativa en el plano del derecho penal del enemigo frente a las distorsiones, cambios y desnaturalización sufridos por esta justicia restaurativa?

El objetivo general que se orientó, fue establecer si los excomandantes de las Farc-EP, frente a las distorsiones, cambios y desnaturalización sufridos por la 
Justicia Especial para la Paz, tienen a esta justicia restaurativa en el plano del derecho penal del enemigo, para explicar su ruptura con este sistema integral; y los objetivos específicos, fueron: Caracterizar la identidad de los excomandantes "Iván Márquez", "Jesús Santrich" y "El Paisa"” en el cuadro de mando las Farc-EP; Identificar las normas, jurisprudencias y doctrina de la Justicia Especial para la Paz en el Acuerdo de Paz firmado por el gobierno de Juan Manuel Santos para destacar las distorsiones, cambios y desnaturalización sufridos por esta justicia restaurativa y Realizar un análisis hermenéutico del derecho penal del enemigo para explicar el retiro de "Iván Márquez", "Jesús Santrich" y "El Paisa” de la Justicia Especial para la Paz.

La hipótesis que orienta esta investigación es, que, además de los demás exguerrilleros de la desmovilizada FARC - EP que anunciaron su regreso a las armas, emitieron su decisión de apartarse de la justicia transicional, posiblemente porque se les ha colocado en el plano del derecho penal del enemigo, por tanto la dirección de las desmovilizadas FARC-EP declara oficialmente que estos excomandantes rompen con el Sistema Integral y no se acogen a lo estipulado en el acuerdo de paz firmado por esta extinta guerrilla y el gobierno colombiano.

\section{El Dispositivo Metodológico}

Esta es una investigación Jurídica Pura y básica para el derecho colombiano, toda vez que atañe al estudio de las normas jurídicas, la jurisprudencia y la doctrina existente en el país y a nivel internacional, para el caso que nos ocupa en estudio de la Justicia Especial para la Paz y el Derecho Penal del Enemigo.

Esta investigación es descriptiva, ya que teóricamente se busca un acercamiento al conocer la realidad del tema investigado, con una relación tiempo-espacial sobre el derecho penal del enemigo, dado que el investigador se centra en realizar una apreciación sobre las características del fenómeno estudiado según (Tantaleán Odar: 2019)

El método que se aplicó es el analítico y de síntesis, que según Tantaleán Odar (2019) es la fragmentación del todo en sus partes elementales con la finalidad de generar nuevo conocimiento, ya que se conoce la estructura del objeto de investigación (los desmovilizados de las FARC) y se descomponen sus elementos constitutivos para ser examinados científicamente dentro de la teoría del derecho penal del enemigo.

En esta investigación no se aplicaron fuentes primarias dado que es una investigación documental o bibliográfica, por lo que se utilizaron las fichas bibliográficas como fuentes secundarias, con las que se recolectó información para elaborar el marco teórico. La información que se recoge en las fichas bibliográficas se reflexionó a través del análisis de contenido. 


\section{Resultados}

En este ítem, se presentan las unidades de análisis que establecieron para el desglose del tema en estudio, "El Ius Puniendi y el derecho penal del enemigo", "los combatientes de las FARC: Enemigos del Derecho Penal Colombiano" y "la Justicia Especial para la Paz en Colombia”, así como las categorías de análisis que como estrategia metodológica se utilizaron para describir el fenómeno que estamos estudiando, pero antes de operacionalizarlas, se realizó una reseña histórica sobre la confrontación armado que ha vivido Colombia por décadas, el cual se agudiza a partir del año 1945, cuando muere asesinado el entonces candidato presidencial Jorge Eliecer Gaitán, evento que produjo un fenómeno que fue llamado como el Bogotazo, con el que se genera el periodo más sangriento de lo que se conoce como violencia política en Colombia, ya que los liberales salen a vengar la muerte de su líder enfrentándose a los conservadores, a quienes acusan de ser sus asesinos y se producen hechos incontrolables de violencia, represión y desórdenes que dejaron no solo semi destruida a Bogotá la capital, sino que es el inicio de la violencia política que reinó en Colombia por más de cincuenta años.

Empezó entonces la violencia armada, y aunque se hizo en Bogotá la capital, un acuerdo entre liberales y conservadores para gobernar el país cada cuatrienio de manera intercalada, a través del fenómeno político que se denominó el Frente Nacional, en regiones lejanas como los llanos orientales, se recrudeció lo que hoy se denominó el conflicto armado, conformándose grupos como los pájaros integrado por campesinos liberales, quienes además se levantaron en armas y formaron sendas columnas guerrilleras, que se enfrentaron los chulavitas, un cuerpo de policía conformados por conservadores.

Estas agrupaciones, según Agudelo (1978) alcanzaron a juntar más de 60.000 mil hombres ubicados en los departamentos cundiboyacenses y de allí surgieron líderes campesinos tales como Fermín Charry a quine llamaron el "Charro Negro", o Pedro Antonio Marín Gómez quien fuera distinguido públicamente como "Manuel Marulanda Vélez" uno de los comandantes guerrilleros más conocidos en el país, al mando de las guerrillas de las FARC $-\mathrm{EP}$.

El conflicto se agudizó durante los gobiernos de Laureano Gómez (Entre 1950 y 1953) y el régimen castrense de Alfonso Rojas Pinillas (Entre 1953 y 1957), regímenes presidenciales que también buscaron llevar a la paz a los grupos guerrilleros. Estos grupos guerrilleros aprovecharon la coyuntura internacional de expansión del comunismo que había surgido en lo que se llamó la Unión Soviética, con el triunfo en América Latina de la Revolución Cubana en 1959, que animó a los varios grupos guerrilleros que existían, a buscar una revolución social con las armas, en un país como Colombia, con 
muchas dificultades políticas y diversas derivaciones sociales que resultaron de la violencia con la cual se desarrollaba el conflicto, uno de estos grupos armados fue las FARC-EP.

Para Agudelo (1978), los cambios que se dieron desde 1959 hasta el año 2012, año en el que las FARC - EP aceptan desmovilizarse, y empezar a negociar el acuerdo de paz en la Habana (Cuba), se destacan por la desmovilización de los bloques revolucionarios, dirigido por diversos comandantes entre otros, los aquí mencionados, que ya en 1964, se consolidaron como las Fuerzas Armadas Revolucionarias de Colombia.

\section{Primera Unidad de Análisis: El Ius Puniendi y el Derecho Penal del Enemigo}

En este ítem, se hace un examen de lo que en las ciencias jurídicas penales se citado como "derecho penal del enemigo", para comprender el ejercicio de la fuerza estatal determinado en la JEP, contra los principales comandantes de las FARC-EP desmovilizados, pero que se apartaron de esta justicia restaurativa, para volver al monte a tomar las armas.

\section{Primera Categoría de Análisis: El Ius Puniendi}

Merlano (2017) aduce, que los aspectos relevantes inmersos en el poder represor del Estado a través del Ius Puniendi, se encuentran inmersos en los disertaciones de la filosofía política, en la que se evidencian teóricamente tanto la existencia misma del Estado, como el derecho de rebelión de sus administrados, aun ante el riesgo que implica el ejercicio de un poder tan amplio para el control social de los asociados, estatuido en la facultad de penalizar y despenalizar las conductas que el derecho penal establece como delitos y obtener su materialización en el proceso penal.

Pero en contraposición a la filosofía política y a partir de los estudios que se han hecho en la ciencia del derecho penal, se han realizado análisis sistematizados de las relaciones que surgen entre los asociados y el Estado en la vida en cotidiana en sociedad, que se han convertido en gélidas discusiones en los foros jurídicos, sobre las maneras en las que la ley faculta a la autoridad judicial, para sancionar a los administrados que violan la ley penal, articulado a un principio del derecho contemporáneo: El respeto por la dignidad humana.

Es diversa la apreciación judicial que hacen los operadores jurídicos, sobre las conductas humanas que son aptas del reproche punitivo estatal, dependiendo de la configuración que se presente en la realidad social de la vida cotidiana (Berger et al: 1968) así será su encuadramiento en las ramas del derecho en las que se encuadra la responsabilidad, ya sea de tipo penal, civil, administrativa, disciplinaria, fiscal, entre otras, ya que el ciudadano está subordinado a que pueda acaecer, el ser sancionado por la autoridad de la ley, 
y el derecho penal tiene el lugar más alto en la graduación valorativa del poder judicial, inclusive, puede autorizar que se restrinja el derecho fundamental a la libertad individual o la vida misma, en aquellos ordenamientos jurídicos, que acreditan la pena de muerte como medida sancionatoria para castigar al delincuente. En contraposición a ese poder punitivo del Estado, se encuentra la garantía del debido proceso, dispuesta en el artículo 29 de la Constitución Política nacional de 1991, que otorga garantías para todas las actuaciones judiciales o administrativas realizadas en Colombia.

\section{Segunda Categoría de Análisis: El Derecho Penal del Enemigo}

Bañuelos (2017), dice que la noción de Derecho Penal del Enemigo, se refiere un régimen penal de excepción que se encarga de controlar socialmente a un sector de la criminalidad, que es de alta peligrosidad, que requiere ser combatido con dispositivos jurídico penales aún más drásticos que los que se contemplan en el derecho penal tradicional, identificando al ciudadano como por ejemplo, a "Iván Márquez", a "Jesús Santrich" y a "El Paisa", excomandantes de las FARC - EP, para distinguirlos como enemigo del Estado, por sus infracciones a la ley durante los enfrentamientos armados con las fuerzas armadas colombianas.

Este sistema penal de excepción tiene como características especiales la mengua de las garantías sustantivas y procesales, que tienen los imputados en el derecho penal, porque los imputados son miembros de la delincuencia organizada y se hacen acreedores a la aplicación de las normas drásticas que se encuentran en legislaciones especiales, que el legislador elabora para combatir el crimen organizado, que también genera terrorismo. El término Derecho Penal del Enemigo fue creado por el penalista alemán Günther Jakobs, y los doctrinantes del derecho penal que le han seguido, han teorizado para evidenciar la necesidad de un orden jurídico penal de tal naturaleza, considerándolo acorde a un Estado de derecho.

\section{Tercera Categoría de Análisis: Los Combatientes de las FARC enemigos del Derecho Penal Colombiano}

Durán (2010) explica, que entre los años 1985 y 1999, el doctrinante Günther Jakobs presentó ante otros teóricos y posteriormente publicó una serie de documentos y realizó ponencias alrededor de muchos países del mundo de la vida - incluida Colombia- en la que explica la noción sociológica de la persona y su insubordinación a ley penal, supuesto teórico en torno al cual gira el derecho penal de enemigo. Sus doctrinas penales gozaron en aquel momento, de alguna resistencia filosófica por parte de juristas, que distinguían que se estaba frente al reavivamiento de posturas que se habían archivado al albor de la modernidad, pero, después del 11 de septiembre de 2001, con el derribamiento de las torres gemelas de Nueva York, en USA, por parte de talibanes o terroristas afganos, el recelo por la seguridad nacional 
se apoderó de las sociedades occidentales como la colombiana y las posturas filosófico-penales de Jakobs, hallaron no solo justificación social en la política criminal de los estados, sino también promotores y defensores de alta talla académica para que se configurara en los ordenamientos penales, la teoría del derecho penal del enemigo.

Es así, como los seguidores de esta teoría jurídico penal, esbozaron el evento de analizar a un Jakobs ya más sofisticado, de fina lección, pero desconfiado, en el cual la representación de lo que sucedía criminalmente en el mundo de la vida (Habermas: 2005) se articulaba con el derecho penal por la determinación de su planteamiento, referente a la prescripción normativa de enemigo del Estado, al delincuente que delinquía sin tener afrenta por el sistema normativo penal, dado que el propósito de este autor, era el de advertir al mundo social actual, sobre los peligros de esta nueva manera de actuar de los delincuentes que generaban terror, para que entendieran cual era la función del derecho penal en un mundo globalizado.

Para otros doctrinantes, entre los que se encontraban los generadores de un derecho penal democrático y liberal, la propuesta teórica de Jakobs no es más que la justificación, de una reducción del ámbito de protección penal en el procesado, reduciéndole las garantías sustantivas y procesales, presentando una manera de instrumentalizar el derecho penal a través de la política imperante en un Estado, en determinado momento social (Durán: 2010)

Es importante comprender, cómo detrás de la aparente "explicación" de los fenómenos de terrorismo, por ejemplo, que se han vivido en el mundo y en Colombia especialmente, a causa del accionar de los diversos grupos guerrilleros como las FARC, por ejemplo, los seguidores de Jacobs encuentran testimonio de la promoción de las experiencias de torturas más degradadas en su uso, contra el ser humano, que infringe la norma penal, sobre todo cuando hacen actos de rebelión contra el Estado, como ocurrió en Colombia, bajo el influjo de los diversos Estados de Sitio ante la protección de la Constitución de 1886.

Esto nos ha llevado a discusiones filosófico-jurídicas, en donde las ideas sobre el derecho penal del enemigo, siente ir de lo tautológico, a la omisión de los supuestos teóricos jurídico penal, que ha sido planteado por las diversas escuelas del derecho penal, a lo largo de su trasegar en la historia de la epistemología, confundida por la doctrina como una forma de evidenciar la ofensiva provisoria contra los terroristas, aplicando la tortura en el delincuente que es considerado enemigo del Estado, como mal menor e institucionalizando la crueldad legal. Con relación a esto, el derecho penal de enemigo ha sido declarado, un dispositivo jurídico penal, en apariencia extraña, pero efectivo e indestructible para validar el derecho a través de la individualización del enemigo, como un individuo -comandante de bloque- o 
un grupo humano -guerrilleros de las FARC-, con los cuales se expone la actividad represiva del derecho, además de su fortaleza legal.

Landazábal (2015) asegura que para Jakobs, el derecho es tan objetivo como la sociedad en que se desarrolla y si lo colocamos en el contexto colombiano, que en su territorio se han desarrollado diversas crisis de violencia -política, armada, etc.- producidas por los tantos grupos al margen de la ley, que han surgido, tanto así como los grupos del narcotráfico, las autodefensas unidas de Colombia, las guerrillas, las Bacrim, etc., que han surgido como diversos fenómenos de criminalidad creciente, no podría hablarse de objetividad en el fallador jurídico penal, porque la sociedad civil ha avanzado con el recelo de que la violencia volverá a desatarse por cualquiera de los actores sociales antes descritos, o por las secuelas que estos mismos desenlazan, como el desplazamiento forzado, la delincuencia común, la marginalidad, el reclutamiento de menores que engrosan las filas de las FARC o ELN, etc.

Aunque el colectivo social colombiano, ha avanzado cotidianamente con la idea del amparo que hace el legislador, al llevar al ordenamiento jurídico las teorías jurídico penales, esta protección se ha logrado, es con las diversas reformas que se le han hecho a la justicia, como por ejemplo, la séptima papeleta, con la que se logró en primera instancia, un plebiscito que instauro la reforma de la Constitución de 1886, y en segunda instancia que el Constituyente primario elaborara una nueva Constitución, la de 1991, fundada en el Estado Social de Derecho, que ha permitido tener tantas leyes como delitos existen en el país, y que ya también incide en la política criminal del Estado, donde se criminalizan y descriminalizan, se penalizan y despenalizan las conductas punibles, que se han aplicado en Colombia. Entonces dependiendo del momento histórico en el que se presentaron los hechos, así se aplicará la ley al sindicado de terrorista, ejemplo claro de lo anterior, es el caso del Palacio de Justicia, que, no obstante que los hechos fueron ocurridos el 6 de noviembre de 1985, algunos de los delitos endilgados al coronel Plazas Vega, son los contenidos en la ley 599 de 2000, como el de "Desaparición Forzada Agravada".

Pero el ordenamiento jurídico colombiano ha pretendido buscar al "enemigo" aún sin saber ¿Quién es?, o ¿Qué daño va a realizar?, esto es resultado de las diversas situaciones jurídicas que Colombia, ha desarrollado frente a la violencia que han utilizado los combatientes de los grupos guerrilleros que han existido en este país latinoamericano, y que dejó muchísimas víctimas, por lo que se prevea que dicho "enemigo" surja y que con su actuar delictual pueda efectuar daño al Estado y a terceros, a través del proceder de su conducta delictiva, se toma como elección jurídico penal retornar a la configuración de un derecho penal del enemigo y sancionar la conducta teniendo en cuenta la peligrosidad del individuo, más no teniendo en cuenta sus actos. 
También el Estado colombiano, ha creado mecanismos judiciales, que están permitidos por la ley, para poder "vigilar" a los individuos, con la finalidad de salvaguardar la seguridad general de la nación, en razón a ello existe la restricción en cierta manera de la privacidad, pues el ente investigador (Fiscalía General de la Nación) tiene facultades para poder allanar la residencia de una persona, cuando en su contra se esté haciendo una investigación penal; así mismo se podrán registrar lugares y realizar la interceptación telefónica, como se ha narrado en diversos casos del extinto DAS, como el caso de las “chuzadas”, excusándose este otrora ente estatal, en el ánimo de adelantar labor la investigativa y de inteligencia, y aún sin que el individuo haya cometido un delito, ya se le estaba vigilando.

Landazábal (2015) asegura, que es bajo el influjo del derecho penal del enemigo, que se ha examinado hacer una analogía entre quienes son sujetos investidos de gran peligrosidad, como por ejemplo, quienes integraron o integran ejércitos armados ilegales o irregulares como las AUC o las variadas guerrillas que existieron en Colombia y que ya están desmovilizadas, frente a aquellos delincuentes que no son peligrosos, es de allí que se fue configurando el ius puniendi frente al cual el Estado colombiano protege la seguridad nacional y la de sus administrados.

Con el ánimo de no llegar al punto de un Estado totalmente autoritario, en Colombia la Constitución de 1991, fundada en el Estado Social de Derecho, se empieza a volcar la atención del legislador, sobre la potestad punitiva o Ius Puniendi, ya que aunque el legislador tiene la libertad de configuración legislativa, no puede llegar a sobrepasar y violar derechos fundamentales de los colombianos, aun cuando estos sean, los desmovilizados comandantes de las FARC, es así como la Corte constitucional, ha esbozado, que el Estado no puede excederse en el ejercicio su poder punitivo, al momento de esbozar las conductas punibles y tampoco puede pasar por encima de los derechos de los individuos a las que se encuentra procesando.

Tal actuación la llevan a cabo los congresistas, en la manera en que se debe evitar cualquier exceso en la pena, que admita que se establezca un injusto penal, frente a quien ha cometido una conducta punible. Landazábal (2015) expone que la relación hecha por Jakobs, sobre el Derecho Penal del Enemigo, no es efectivo en Colombia, porque frente al Estado Social de Derecho, el legislador al realizar la configuración legislativa de las conductas penales no puede transgredir los derechos constitucionales, que el delincuente tiene, así sea este un temible comandante de la guerrilla más belicosa que tuvo Colombia, en los tiempos de las confrontaciones armadas.

Recordemos, que las Fuerzas Armadas Revolucionarias de Colombia, Ejercito del Pueblo FARC - EP, era una organización guerrillera, que en sus inicios se planteaba bajo los parámetros de la filosofía marxista - leninista, y buscaba acabar con las desigualdades sociales, políticas y económicas, así 
como la intervención militar y económica de los Estados Unidos. Esta era a su vez una guerrilla rural, con algunas células urbanas sobre todo en ciudades donde imperaba la miseria y la marginalidad. Su accionar era el de la guerra de guerrillas y combate regular y convencional, pero posteriormente se aliaron con narcotraficantes y fueron consideradas, como una agrupación terrorista no solo en Colombia, sino en 31 países del mundo, entre ellos, los países de la Unión Europea, Chile, Perú, Canadá y Estados Unidos.

\section{Segunda Unidad de Análisis: La Justicia Especial para la Paz en Colombia}

La JEP, es el mecanismo judicial del Sistema Integral de Verdad, Justicia, Reparación y No Repetición (SIVJRNR), instituido en el Acuerdo de Paz con el que se buscó la terminación del conflicto armado en el que participaban las Fuerzas Armadas Revolucionarias de Colombia FARC - EP y el gobierno de Juan Manuel Santos, para construir una paz estable y duradera. Este un mecanismo de justicia transicional, que tiene la tarea de investigar, esclarecer, juzgar y sancionar los más graves crímenes de lesa humanidad, ocurridos en Colombia en manos de los excombatientes de esta guerrilla, durante los más de 50 años de conflicto armado, y hasta el 1 de diciembre de 2016.

La justicia transicional, está organizada por un conjunto de medidas judiciales, que otros países que también han vivido conflicto armado, han esgrimido como un procedimiento para enjuiciar, las graves violaciones a los derechos humanos, los crímenes de guerra y los crímenes de lesa humanidad ocurridas en un conflicto armado, por eso es transicional, ya que temporalmente permite que los actores armados, acogidos en esta justicia, vivan una transición para reinsertarse nuevamente en la sociedad.

En esos contextos de guerra, barbarie y terrorismo, es necesario construir un mecanismo transitorio, para que los responsables de crímenes de guerra lleguen de una manera efectiva a rendir cuentas por su accionar delictivo y terrorista y se pueda garantizar a sus víctimas, acceder al derecho a la saber la verdad de la ocurrencia de los hechos del injusto penal, y así se le aplique la justicia, para que repare sus actos dañosos y se garantice la no repetición de estos. La justicia transicional tiene en el centro de su trasegar a las víctimas, es por ello, por lo que escucha sus relatos sobre el daño sufrido y les examina sus derechos, para reconocerlos, ya que busca el restablecimiento del derecho, que según Salcedo (2019) es una figura jurídica vista en la ley procesal penal, que explora proteger, en todo momento, los derechos de las víctimas en el proceso criminal.

\section{Discusión}

Para el inicio de la discusión científica sobre el tema objeto de este documento, es bueno acotar, que Günther Jakobs escribió un libro titulado, 
Derecho Penal del Enemigo, con Thomson Civitas y traducido al idioma español por Cancio Meliá Manuel (2003); documento en el que dicen estar de acuerdo con una cómoda ilusión, "en que todos los seres humanos se hallan vinculados entre sí por medio del Derecho en cuanto personas y que esta suposición es cómoda porque exime de la necesidad de empezar por comprobar en qué casos se trata en realidad de una relación jurídica y en cuáles otros de una situación a jurídica" (p34).

Para estos autores, semejante al escenario respecto del derecho en sí mismo, es la de las instituciones que crea, y esencialmente de las personas a las que quiere regular penalmente: "si ya no existe la expectativa seria, que tiene efectos permanentes de dirección de la conducta, de un comportamiento personal -determinado por derechos y deberes-, la persona degenera hasta convertirse en un mero postulado, y en su lugar aparece el individuo interpretado cognitivamente" (2003).

Lo anterior explica la conducta cognitiva del individuo infractor, en el mundo subjetivo, que decanta la aparición del individuo peligroso, que se convierte en el enemigo del Estado, como, por ejemplo, el delincuente que permanentemente delinque, y lo hace una y otra vez, siendo sus delitos más que bagatelas, se le tiene como un individuo peligroso al momento de la imposición de la pena, por lo que no podrá cometer posteriores hechos, porque se la custodia en cárceles de alta seguridad. Hablando en términos kantianos, según Vigo (2011) hay que apartar a quien no consiente ser incluido, en una sociedad civil, como miembro de la sociedad en que vive.

Palacios Valencia (2010) considera que la discusión sobre el derecho penal del enemigo, está revolucionando el mundo del derecho penal, en general y el derecho penal internacional en particular, ostentando, "que este debate está llamando la atención de la comunidad académica penalista, en tanto se plantea y se vislumbra un problema de fondo, no solo por la seguridad nacional y de los asociados del Estado, sino también en cuanto a la efectiva protección de los derechos humanos, por encima de un discurso de seguridad naciona"l, situación que se viene planteando en la lucha contra el terrorismo en la comunidad internacional, y en la política criminal al interior de Estados, que dicen llamarse democráticos.

$\mathrm{Y}$ es que esta situación académica, está revolucionando la concepción tradicional del derecho, dado que se confronta la violación de la dignidad humana, por ejemplo, en Colombia, como eje central del Estado Social de Derecho, al poner en práctica lo que Jakobs (2003) denomina “derecho penal del enemigo".

López Capdevila (2015) considera a su vez, que este es un derecho penal destinado, no a la resocialización del delincuente, sino a la inocuización de unos tipos de delincuentes, que son catalogados como enemigos del Estado e 
incluso considerados como "no-personas" a los que hay que tratar como tal. Esta doctrina ha sido llamada "Derecho penal del enemigo", la misma que posiblemente no tiene en cuenta elementos, del actual contexto socioeconómico que pueden favorecer este tipo de soluciones, más bien son expresiones jurídico penales propios de países totalitarios.

Parra (2016) considera, que algunos estudiosos afirman, que la política criminal aplicada históricamente en Colombia, en los años ochenta, bajo el amparo del Estado de Sitio, que la Constitución de 1886, fundada en el Estado de Derecho, en su influjo constitucional, ostenta varias de las peculiaridades que caracterizan al derecho penal de enemigo, sobre todo, aquellas que permiten el esparcimiento del derecho penal fundado en el aumento de la punibilidad de las conductas punibles reguladas en la ley penal, en las cuales se hace un recorte imperceptible de los derechos y las garantías de los ciudadanos, que se convierten en delincuentes, como los guerrilleros de las FARC.

Y Víquez, (2007), hace una brevísima disertación de las vitales particularidades, que sitúan la noción que el profesor Günther Jakobs, denomina derecho penal del enemigo y confronta el citado derecho al concepto de ilusión filosófica, al determinar que esta doctrina es una mera descripción jurídico penal, que tienes elementos conceptuales ilusorias, que no se pueden aplicar en muchos Estados, sobre todo en Colombia, que vive muchas crisis en su cotidianidad sociopolítica. Finalmente, puntualiza en la necesidad de reflexionar sobre el futuro de un derecho penal, a merced de la protección de peligros y no de las libertades de sus asociados.

Landazábal Gómez (2015) hace una correlación, de las relaciones entre el derecho penal y el "enemigo", como nociones tocantes a fenómenos de creciente ocurrencia en una colectividad demócrata como la colombiana, ya que lo planteado por Günther Jakobs, se conoce como derecho de autor, y si se contrasta con otra perspectiva teórica que es planteado por Claux Roxin (2019), y se conoce como el derecho de acto, destaca, que estas dos posiciones, han sido traídas a nuestro ordenamiento jurídico, lo que evidencia que Colombia no tenga una teoría jurídico penal definida a la hora de aplicar el derecho penal, porque algunas veces es un derecho de autor, y otras es el derecho de acto, requiriendo que se haga una deliberación científico académica al respecto, con relación a la prevención del delito, como respuesta estatal de la política criminal, mas no al ius puniendi como practica legislativa en un Estado como el colombiano, que también cuenta con garantías y derechos constitucionales para sus ciudadanos, en la Constitución de 1991.

Y relacionando en este análisis, si los comandantes de las FARC-EP ante la JEP, están en el plano del derecho penal del enemigo, encontramos a Sampedro-Arrubla (2010) quien aporta opiniones, sobre la justicia restaurativa, como una herramienta jurídica que hace viable la búsqueda de 
una solución negociada de la confrontación armada, que por años ha vivido Colombia, para crear nuevas formas de convivencia. Así mismo, Ríos Martín et al (2011), intentan brindar una deliberación sobre los supuestos filosófico jurídicos de la justicia restaurativa, como prototipo transformador de la justicia penal, abordando asuntos de la realidad cotidiana colombiana de preeminencia jurídico-penal, exponiendo sus principios y explicando las posibilidades que los procesos restaurativos conceden a las propias personas infractoras de la ley, a las víctimas de estos y a la comunidad en general, para la resolución pacífica de conflictos de índole penal.

Valencia et al (2018), aduce que, luego de varios años de negociación, el Gobierno Colombiano y las FARC-EP pactaron finalizar el conflicto armado interno, considerado uno de más largo de América Latina, y en el establecieron mecanismos de justicia transicional, que quedaron instituidos en la JEP. Esto se logó con la finalidad de juzgar y sancionar a aquellos que ejecutaron conductas penales en el marco del conflicto armado, tales como los excombatientes de las FARC- EP. Estos recibirían sanciones no precisamente privativas de libertad.

Esta jurisdicción especial recibió muchísimas críticas y no fue refrendada por los colombianos, en el plebiscito en el que se les consultó si respaldaban el acuerdo, y en el que ganó el "NO", se conceptúa que solo por estas razones, no se podría afirmar que carece de legalidad política, ya que es una institución judicial que suspende la justicia penal ordinaria de un Estado social y democrática de derecho, para aplicar transitoriamente la justicia retributiva; y su marco jurídico estipula, que se crea con el propósito de superar el conflicto armado y transitar hacia la paz, estable y duradera, requiera estar auténticamente justificada, ya que el derecho humano a la paz se presenta como derecho reconocido desde el derecho internacional, y su materialización genera la realización de una vida plena, según Caro Benítez (2019)

Sobre las Fuerzas Armadas Revolucionarias FARC - EP, encontramos que Pataquiva (2009), aduce que, en Colombia no solo se viven conflictos sociales que lo han afectado como nación, sino que accionar delictivos tales como el narcotráfico, el terrorismo, el secuestro, y los actores sociales que como grupos armados, han creado terror con su maniobrar, crecieron de manera tal, que acabaron perturbando no solo la seguridad y la paz de los ciudadanos que se localizaban viviendo su cotidianidad en apartadas regiones selváticas, sino a comunidades limítrofes, como las peruanas o venezolanas.

$\mathrm{Y}$ es que las intimidaciones terroristas, que ha resistido los Estados del llamado tercer mundo, son análogas en esencia, pero de particularidades y avance diferentes al interior de cada uno, pero que así mismo asume este autor (p15) que el drama socio político colombiano, es ya distinguido en el mundo de la vida y las FARC-EP, son distinguidas como una de las guerrillas belicosas más antiguas del mundo. 


\section{Conclusión}

Luego de ser una de las guerrillas más beligerante de Colombia, las Fuerzas Armadas Revolucionarias de Colombia FARC - EP, en el año 2012, empiezan un proceso de paz con el gobierno de Colombia en cabeza de Juan Manuel Santos, el cual concluyó con la firma de un acuerdo de paz, que buscaba la dejación de las armas de todos los integrantes de este grupo armado y poner fin al conflicto armado, que por más de cincuenta años vivió crudamente este país de Latinoamérica.

Es así como, los exintegrantes de las FARC - EP, empezaron un proceso de desmovilización con entrega de las armas que utilizaron para la beligerancia y se prepararon para su reingreso a la vida civil. Algunos de ellos, los excombatientes, construyeron asentamientos de exguerrilleros, conformados como exintegrantes de los frentes que conformaban, en la estructura militar del ya extinto grupo guerrillero. Ya no visten con el uniforme camuflado, visten como viste cualquier parroquiano de un pueblo colombiano.

Pero después de la firma del acuerdo de paz y ya en el ejercicio de la vida política en el nuevo partido político F.A.R.C varios de sus jefes de comandos, tales como alias "Iván Márquez", Alias "El Paisa" y alias "Jesús Santrich", notificaron que constituirían un nuevo grupo guerrillero, como disidente de las extintas FARC-EP y que no se someterían a los procesos de la justicia especial para la paz (JEP) que como justicia transicional, se estructuró para que judicialmente fueran procesados, por ello, al pretenderse establecer si los mencionados excomandantes de las Farc-EP frente a las distorsiones, cambios y desnaturalización sufridos por la mencionada justicia especial, tienen a esta justicia restaurativa en el plano del derecho penal del enemigo, para explicar su ruptura con este sistema integral, se puede alegar que sí, ellos no creyeron en la justicia colombiana y quisieron además seguir delinquiendo.

\section{Bibliografía}

Agudelo C., Carlos. El Salvador, Una Tregua Tensa, Alternativa n. ${ }^{\circ} 240$, Bogotá, 22 a 29 de noviembre de 1979.

Bañuelos Rodríguez Adrián Said. Análisis del Principio de Proporcionalidad de la Pena en el Código Penal para el Estado de Nayarit. Tesis de Grado para optar el Titulo de Maestro. Maestría en Derecho Penal. Universidad Autónoma de Nayarit. México. 2017.

Berger, P., \& Luckmann, T. (1968). La Construcción Social de la Realidad (2. ${ }^{a}$ ed.). Amorrortu.

Caro Benítez, M. J. (2019). La Justicia Transicional y la Construcción de Paz: Reflexiones en torno a su Garantía en el Postconflicto Colombiano. Revista 
Jurídica Mario Alario D’Filippo, 11(22), 204-216. https://doi.org/10.32997/2256-2796-vol.11-num.21-2019-2510

Durán Puentes Julián Andrés. Acerca del Derecho Penal del Enemigo como Expresión Jurídica de una actividad denegada. Gunter Jakobs y el asalto al Derecho Penal. Pap. Polít. Bogotá (Colombia), Vol. 15, No. 2, 513-535, juliodiciembre 2010.

Habermas, Jürgen (2005): Facticidad y Validez. Sobre el Derecho y el Estado Democrático de Derecho en términos de Teoría del Discurso ( $4^{\mathrm{a}}$ edición, Madrid, Editorial Trotta) $689 \mathrm{p}$.

Jakobs, Günther. "Derecho Penal del Ciudadano y Derecho Penal del Enemigo". Traducido por Cancio Meliá, Manuel. En: Jakobs, Günther; Cancio Meliá, Manuel. Derecho Penal del Enemigo. Madrid: Civitas, 2003, p. 102, p. 22.

Landazábal Gómez Diana Yolima. Derecho Penal del Enemigo desde el concepto de Jakobs versus la perspectiva de Roxin y su aplicación en Colombia. Articulo Para Optar por el Título de Especialista en Derecho Penal. Universidad Militar Nueva Granada. Especialización en Procedimiento Penal, Constitucional y Justicia Militar. Bogotá. 2015.

López Capdevila Javier. Derecho Penal del Enemigo: La Sombra del Autoritarismo en la Política Criminal contemporánea. Universidad de Barcelona. Trabajo de Fin de Grado. $4^{\circ}$ Curso del Grado en Derecho. 2015.

Merlano Sierra Javier Enrique. Aspectos Generales de la Potestad Punitiva del Estado: La Identidad Sustancial entre Delitos e Infracciones Administrativas y la Aplicación Analógica de la Ley. Primera Edición Editorial Corporación Universidad de la Costa, EDUCOSTA. 2017.

Molina Sierra, G. M. (2018). Causas de reincidencia en los delitos de los menores en el SRPA, en la ciudad de Cartagena entre los años 2012 y 2015. Revista Jurídica Mario Alario D’Filippo, 10(19), 126-155. https://doi.org/10.32997/2256-2796vol.10-num.19-2018-2163

Palacios Valencia Yennesit. Existencia del Derecho Penal del Enemigo en el Derecho Penal Internacional. Revista Latinoamericana de Derechos Humanos Vol. 21 (2): 19, julio-diciembre, 2010 (ISSN: 1659-4304)

Pataquiva García, Germán Nicolás Las FARC, su Origen y Evolución UNISCI Discussion Papers, núm. 19, enero, 2009, pp. 154-184 Universidad Complutense de Madrid, Madrid - España. Disponible en: https://www.redalyc.org/articulo.oa?id=76711407010

Parra, W. J. (2016). El Derecho Penal y la Política Criminal de Enemigo en Colombia. Derecho Y Realidad, 4(8). Recuperado a partir de https://revistas.uptc.edu.co/index.php/derecho_realidad/article/view/5174

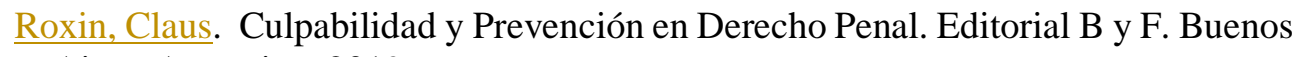
Aires. Argentina. 2019. 
Ríos Martín, J. C. (1). Justicia Restaurativa y Mediación Penal. Icade. Revista De La Facultad De Derecho, https://doi.org/10.14422/icade.i98.y2016.004

(98), 103-126.

Salcedo Alarcón, M. (2020). La figura del Restablecimiento del Derecho en el Sistema Penal Acusatorio. Revista Jurídica Mario Alario D'Filippo, 12(23), 5680. https://doi.org/10.32997/2256-2796-vol.12-num.23-2020-2655

Tantaleán Odar Reynaldo Mario. El Problema de Investigación Jurídica. Revista Derecho y Cambio Social N. ${ }^{\circ}$ 57, jul-set 2019. ISSN: 2224-4131.

Valencia Paula A. y Francés-Gómez Pedro. Legitimidad de la Jurisdicción Especial para la Paz. http://dx.doi.org/10.30827/revpaz.v11i1.6027 ISSN 1988-7221. Vol. 11. No 1. 2018. pp. 105-133

Vigo, Alejandro G. (2011). Ética y Derecho según Kant. Tópicos (México), (41), 105-158. Recuperado en 02 de octubre de 2021, de http://www.scielo.org. mx/scielo.php?script=sci arttext\&pid=S0188$\underline{66492011000200004 \& \operatorname{lng}=\mathrm{es} \& \operatorname{tlng}=\mathrm{es}}$

Víquez, Karolina. Derecho Penal del Enemigo ¿Una quimera dogmática o un modelo orientado al futuro?". Polít. Crim. $\mathrm{n}^{\mathrm{o}} 3$, 2007, A2, p. 1-18. [http://www.politicacriminal.cl] 